\title{
Blockade of stress-induced increase of glutamate release in the rat prefrontal/frontal cortex by agomelatine involves synergy between melatonergic and $5-\mathrm{HT}_{2 \mathrm{C}}$ receptor-dependent pathways
}

\author{
Daniela Tardito1, Marco Milanese², Tiziana Bonifacino², Laura Musazzi', Massimo Grilli2, Alessandra Mallei', \\ Elisabeth Mocaer³, Cecilia Gabriel-Gracia33, Giorgio Racagni1,4, Maurizio Popoli*1 and Giambattista Bonanno²
}

\begin{abstract}
Background: Agomelatine is a melatonergic receptor agonist and a $5 \mathrm{HT}_{2}$ receptor antagonist that has shown antidepressant efficacy. In order to analyze separately the effect of the two receptorial components, rats were chronically treated with agomelatine, melatonin (endogenous melatonergic agonist), or S32006 (5-HT 2 antagonist), and then subjected to acute footshock-stress.
\end{abstract}

Results: Only chronic agomelatine, but not melatonin or \$32006, completely prevented the stress-induced increase of glutamate release in the rat prefrontal/frontal cortex.

Conclusions: These results suggest a potential synergy between melatonergic and serotonergic pathways in the action of agomelatine.

\section{Background}

Despite the improved tolerability of newer antidepressants such as the selective serotonin reuptake inhibitors (SSRIs) [1-4] and the dual serotonin-norepinephrine reuptake inhibitors (SNRIs), adverse events associated with their use can influence adherence rates. There is an unmet need for a better understanding of the mechanisms and therapeutic management of depression, as well as for treatments with improved efficacy and tolerability. Indeed, both the pathophysiology of depression and the exact mechanisms whereby antidepressants elicit a therapeutic response have not been fully explored. An increasing body of evidence indicates that depression is associated with a disruption of circadian rhythms, suggesting that resetting of disrupted circadian rhythms may

*Correspondence: maurizio.popoli@unimi.it

${ }^{1}$ Center of Neuropharmacology - Department of Pharmacological Sciences and Center of Excellence on Neurodegenerative Diseases, University of Milano, Italy

Full list of author information is available at the end of the article play a pivotal role in the treatment of this condition [511]. Agomelatine is a melatonergic receptor (MT1/MT2) agonist [12] and $5 \mathrm{HT}_{2 \mathrm{C}}$ receptor antagonist [13] that has showed antidepressant efficacy in animal models [14-17] and clinical trials [18-21].

Recent findings have shown that, in addition to the changes induced in monoamine transmission, antidepressants may work by modulating glutamate release and transmission in relevant limbic and cortical areas [22-24]. In this regard, we have previously found that different chronic antidepressant treatments (including agomelatine) abolish the increase of depolarization-evoked glutamate release, induced by acute footshock (FS)-stress, from synaptosomes of prefrontal/frontal cortex (P/FC) $[25,26]$. Here we studied the two separate components in the mechanism of agomelatine, by treating rats chronically with either agomelatine, or melatonin (the endogenous agonist of MT1/MT2 receptors), or S32006 (a selective $5-\mathrm{HT}_{2 \mathrm{C}}$ antagonist), and then subjected the rats 
to FS-stress as above. Aim of the experiments was to investigate whether one of the two receptorial components was sufficient for the dampening action of agomelatine on stress-induced glutamate release, or both components were necessary. We found that chronic treatment with either melatonin or S32006 did not significantly reduce the stress-induced glutamate release, while chronic agomelatine treatment, as observed previously, completely abolished the stress-induced glutamate release, suggesting a potential synergy between MT1/ MT2- and 5- $\mathrm{HT}_{2 \mathrm{C}}$-dependent pathways in the action of agomelatine.

\section{Results}

Depolarization-evoked release of glutamate from P/FC synaptosomes is increased after acute footshock stress

After chronic drug treatments, rats were subjected to standard acute FS-stress protocol (see Methods) and, immediately after the stress session, the synaptosomes were purified from $\mathrm{P} / \mathrm{FC}$. The presynaptic release of endogenous glutamate and GABA evoked by $15 \mathrm{mM} \mathrm{KCl}$ were measured from synaptosomes in superfusion, as done previously $[22,25,26]$. One way ANOVA showed significant difference among groups $\left(\mathrm{F}_{4,30}=6.757 ; \mathrm{p}<\right.$ 0.0005). Indeed, acute FS-stress increased depolarization-dependent release of endogenous glutamate from $\mathrm{P} /$ FC synaptosomes (45.9\%) and, as previously observed with several different antidepressants [25,26], chronic agomelatine treatment completely prevented the stressinduced increase of glutamate release (Figure. 1). In the previous work [26] we also observed that agomelatine, as

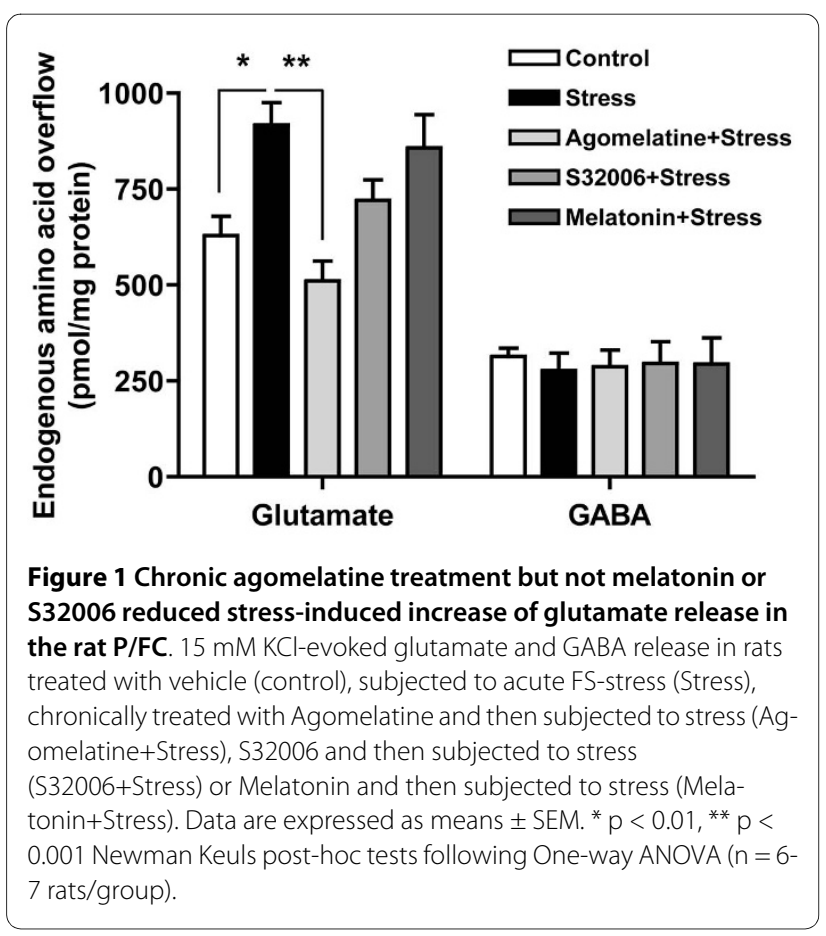

well as other antidepressants, did not modify glutamate release from $\mathrm{P} / \mathrm{FC}$ synaptosomes in non-stressed rats (not shown here). For this reason agomelatine treatment of non-stressed rats was not replicated here; similarly melatonin or S32006 treatment of non-stressed rats was not performed here. Having agomelatine per se no effect on glutamate release in $\mathrm{P} / \mathrm{FC}$ in the absence of stress, there was no point in testing if either of the two other compounds per se may modify glutamate release. As shown in Figure 1, in rats treated with melatonin and then stressed, the release of glutamate was similarly increased as in stressed rats. In rats treated with S32006 (antagonist of $5-\mathrm{HT}_{2 \mathrm{C}}$ receptor) a trend for reduction of stress-induced glutamate release was observed $(-70 \%)$ but the compound did not significantly dampen stressinduced glutamate release. No significant changes in GABA release were induced by either FS-stress or any of the drugs. No effect of acute agomelatine treatment (same dose) was found on FS-stress increased release of endogenous glutamate.

\section{Discussion and Conclusion}

In this study we sought to dissect the action of different receptorial components of agomelatine, with regard to the action of this drug on stress-induced glutamate release in P/FC. This was carried out by performing chronic treatments with either melatonin or a selective 5$\mathrm{HT}_{2 \mathrm{C}}$ receptor antagonist (S32006), both endowed with receptorial affinity comparable with the affinity of agomelatine for the respective receptors. The present results, showing that only agomelatine but not the two other compounds significantly prevented the stress-induced increase of glutamate release, suggest that the action of agomelatine on glutamate release requires both receptorial components. However, it is worth noting that while glutamate release in melatonin-treated rats was virtually indistinguishable from stressed rats, in rats treated with S32006 a trend for reduction of release was observed ($70 \%$ compared to stress group). It may be speculated that enhancement of noradrenergic and dopaminergic transmission induced by $5-\mathrm{HT}_{2 \mathrm{C}}$ receptor antagonism [13] in cortical areas is a necessary modification for dampening of glutamate release, similar to the outcome of treatments with monoamine reuptake inhibitors, which also increase monoamine neurotransmission with a different mechanism [for a discussion see ref. $[27,28]]$. However, in the case of agomelatine only the combination of melatonergic agonism with $5-\mathrm{HT}_{2 \mathrm{C}}$ receptor antagonism seems to be sufficient for full blockade of stress-induced glutamate release. This is in turn suggestive of a possible synergy between melatonin and $5-\mathrm{HT}_{2 \mathrm{C}}$ receptor-dependent pathways in the action of this drug. 
These results are in line with the behavioral data published by Papp et al. [17], showing that the antidepressive effects of agomelatine in the chronic mild stress model of depression depend on a combination of its melatonin agonist and $5 \mathrm{HT}_{2 \mathrm{C}}$ antagonist properties. Furthermore, comparable results were also obtained in the learned helplessness model of depression, where antidepressant effect was observed with agomelatine, but not after treatment with melatonin or the selective $5-\mathrm{HT}_{2 \mathrm{C}}$ antagonist SB242084 [14]. In this line, recently it has been demonstrated that the effects of chronic agomelatine on cell survival in hippocampus as well as on Brain Derived Neurotrophic Factor (BDNF) expression maybe due to a synergy between both properties of the drug $[29,30]$.

Further studies, at the level of intracellular signaling and of presynaptic machinery $[22,31,25,26]$, will investigate the suggested cross-talk between post-receptor pathways in the action of agomelatine on glutamate release.

\section{Methods}

\section{Footshock stress procedure and drug treatments}

Sprague-Dawley rats (170-200 gr) were purchased from Charles River (Calco, Italy). All experimental procedures were performed in accordance with the European Community Council Directive 86/609/EEC and Italian legislation on animal experimentation (Decreto Ministeriale 124/2003-A). Rats were chronically (14 days) treated with agomelatine (40 mg/kg i.p.), melatonin (40 mg/kg i.p.), S32006 (10 mg/kg i.p.), or vehicle (hydroxyethylcellulose, $1 \%, 1 \mathrm{ml} / \mathrm{Kg}$, i.p.), administered at $5.00 \mathrm{pm}$ ( $2 \mathrm{~h}$ before the start of the dark cycle, $7 \mathrm{pm}$ ). The doses of agomelatine and melatonin were selected based on their reported activities in animal models of depression [17,14], and on their effect on neurogenesis [29]. Similarly, the dose of S32006 was chosen based on previous works showing antidepressant activity on neurogenesis and BDNF $[29,30]$, as well as on its activity on 5-HT2c receptors in vivo and on neurogenesis [32].

The FS-stress protocol was performed $16 \mathrm{~h}$ after the last administration, essentially as reported in ref. 33 (40min FS-stress; $0.8 \mathrm{~mA}, 20$ min total of actual shock with random intershock length between 2-8 sec). The FSstress box was connected to a scrambler controller (LE 100-26, Panlab) that delivers intermittent shocks to the metallic floor. Sham-stressed rats (controls) were kept in the stress apparatus without delivering of shocks. Rats were killed immediately after FS-stress and P/FC were quickly dissected on ice and processed as reported below.

\section{Preparation of purified synaptosomes for glutamate/GABA release}

Purified synaptic terminals (synaptosomes) were prepared by centrifugation on Percoll gradients [34,22] from fresh brain tissue, and resuspended in physiological medium with the following composition $(\mathrm{mM}): \mathrm{NaCl}$, 125; KCl, 3; $\mathrm{MgSO}_{4}, 1.2 ; \mathrm{CaCl}_{2}, 1.2 ; \mathrm{NaH}_{2} \mathrm{PO}_{4}, 1$; $\mathrm{NaHCO}_{3}$, 22; glucose, 10 (aeration with 95\% $\mathrm{O}_{2}$ and $5 \%$ $\mathrm{CO}_{2}$ ); $\mathrm{pH}$ 7.2-7.4.

\section{Glutamate and GABA release experiments}

Aliquots of the synaptosomal suspensions (about $100 \mu \mathrm{g}$ protein) were layered on microporous filters at the bottom of a set of parallel superfusion chambers maintained at $37^{\circ} \mathrm{C}[35,36]$. Superfusion was started at a rate of 0.5 $\mathrm{ml} / \mathrm{min}$ with standard medium aerated with $95 \% \mathrm{O}_{2}$ and $5 \% \mathrm{CO}_{2}$. After $36 \mathrm{~min}$ of superfusion, to equilibrate the system, samples were collected according to the following scheme: two 3-min samples $(t=36-39$ min and $t=45-48$ min; basal outflow) before and after one 6-min sample ( $t$ = 39-45 min; stimulus-evoked release). A 90-sec period of stimulation was applied at $\mathrm{t}=39 \mathrm{~min}$, after the first sample has been collected. Stimulation of synaptosomes was performed with $15 \mathrm{mM} \mathrm{KCl}$, substituting for equimolar concentration of $\mathrm{NaCl}$. Fractions collected were analysed for endogenous glutamate and GABA content. Amino acid release was expressed as $\mathrm{nmol} / \mathrm{mg}$ of protein. The stimulus-evoked overflow was estimated by subtracting transmitter content of the two 3-min samples (basal outflow) from release evoked in the 6-min sample collected during and after the depolarization pulse (stimulusevoked release). Effects of drug treatments were evaluated by comparing the stimulus-evoked overflow in drugtreated animals vs. that calculated in vehicle-treated rats. Appropriate controls were always run in parallel. Endogenous glutamate and GABA were measured by high performance liquid chromatography analysis [22].

\section{Statistical analysis}

One-way analysis of variance (ANOVA) was used for the analysis of glutamate release followed by post-hoc group comparisons with Newman Keuls test. Statistical analysis of the data was carried out using GraphPad Prism4 (GraphPad Software Inc., USA). For all analyses a value of $\mathrm{p}<0.05$ was considered statistically significant.

\section{Abbreviations}

SSRI: Selective serotonin reuptake inhibitor; SNRI: Serotonin-norepinephrine reuptake inhibitor; FS: Footshock; P/FC: Prefrontal/frontal cortex; BDNF: Brain Derived Neurotrophic Factor.

\section{Authors' contributions}

MP, GB and GR designed the study. MP, DT and LM wrote the ms. LM, MM, TB, $M G, A M$ performed all the experimental work. DT performed the statistical analysis. EM, CG participated on the study design as well as on the paper discussion. All authors read and approved the final manuscript.

\section{Acknowledgements}

This study was supported by grants from the Italian Ministry of University and Research, PRIN no. 2003053993 and 2005054953, and a research grant from Servier. 


\section{Author Details}

${ }^{1}$ Center of Neuropharmacology - Department of Pharmacological Sciences and Center of Excellence on Neurodegenerative Diseases, University of Milano, Italy, 2Department of Exp. Medicine, Section of Pharmacology and Toxicology and Center of Excellence for Biomedical Research and National Institute of Neuroscience, University of Genova, Italy, ${ }^{3}$ IDR Servier, Croissy-sur-Seine, France and ${ }^{4}$ I.R.C.C.S San Giovanni di Dio - Fatebenefratelli, Brescia, Italy

Received: 12 January 2010 Accepted: 3 June 2010

Published: 3 June 2010

\section{References}

1. Anderson IM: Selective serotonin reuptake inhibitors versus tricyclic antidepressants: a meta-analysis of efficacy and tolerability. J Affect Disord 2000, 58:19-36.

2. Danish University Antidepressant Group: Paroxetine: a selective serotonin reuptake inhibitor showing better tolerance, but weaker antidepressant effect than clomipramine in a controlled multicenter study. Danish University Antidepressant Group. J Affect Disord 1990, 18:289-99.

3. Sonawalla SB, Fava M: Severe depression: is there a best approach? CNS Drugs 2001, 15:765-76.

4. Vestergaard P, Gram LF, Kragh-Sorensen P, Bech P, Reisby N, Bolwig TG: Therapeutic potentials of recently introduced antidepressants. Danish University Antidepressant Group. Psychopharmacol Ser 1993, 10:190-198.

5. Kupfer DJ: Sleep research in depressive illness: clinical implications--a tasting menu. Biol Psychiatry 1995, 38:391-403.

6. Lopes MS, Quera-Salva MA, Guilleminault C: Non-REM sleep instability in patients with major depressive disorder: subjective improvement and improvement of non-REM sleep instability with treatment (Agomelatine). Sleep Medicine 2007, 9:34-41

7. Lam RW: Sleep disturbances and depression: a challenge for antidepressants. Int Clin Psychopharmacol 2006, 21 (Suppl 1):S25-S29.

8. Souetre E, Salvati E, Wehr TA, Sack DA, Krebs B, Darcourt G: Twenty-fourhour profiles of body temperature and plasma TSH in bipolar patients during depression and during remission and in normal control subjects. Am J Psychiatry 1998, 145:1133-1137.

9. Tsuno N, Besset A, Ritchie K: Sleep and depression. J Clin Psychiatry 2005, 66:1254-1269

10. Van CE, Turek FW: Depression: a disorder of timekeeping? Perspect Biol Med 1986, 29:510-519.

11. Wirz-Justice A: Biological rhythm disturbances in mood disorders. Int Clin Psychopharmacol 2006, 21(Suppl 1):S11-S15.

12. Audinot V, Mailliet F, Lahaye-Brasseur C, Bonnaud A, Le Gall A, Amosse C, Dromaint S, Rodriguez M, Nagel N, Galizzi JP, Malpaux B, Guillaumet G, Lesieur D, Lefoulon F, Renard P, Delagrange P, Boutin JA: New selective ligands of human cloned melatonin MT1 and MT2 receptors. Naunyn Schmiedebergs Arch Pharmacol 2003, 367:553-561.

13. Millan MJ, Gobert A, Lejeune F, Dekeyne A, Newman-Tancredi A, Pasteau $V$, Rivet JM, Cussac D: The novel melatonin agonist agomelatine (S20098) is an antagonist at 5-hydroxytryptamine2C receptors, blockade of which enhances the activity of frontocortical dopaminergic and adrenergic pathways. J Pharmacol Exp Ther 2003, 306:954-964

14. Bertaina-Anglade V, la Rochelle CD, Boyer PA, Mocaer E: Antidepressantlike effects of agomelatine (S 20098) in the learned helplessness model. Behav Pharmacol 2006, 17:703-713.

15. Bourin M, Mocaer E, Porsolt R: Antidepressant-like activity of S 20098 (agomelatine) in the forced swimming test in rodents: involvement of melatonin and serotonin receptors. J Psychiatry Neurosci 2004 29:126-133.

16. Barden N, Shink E, Labbe M, Vacher R, Rochford J, Mocaer E: Antidepressant action of agomelatine (S 20098) in a transgenic mouse model. Prog Neuropsychopharmacol Biol Psychiatry 2005, 29:908-916.

17. Papp M, Gruca P, Boyer PA, Mocaer E: Effect of agomelatine in the chronic mild stress model of depression in the rat. Neuropsychopharmacol 2003, 28:694-703.

18. Goodwin GM, Emsley R, Rembry S, Rouillon F: Agomelatine prevents relapse in patients with major depressive disorder without evidence of a discontinuation syndrome: a 24-week randomized, double-blind, placebo-controlled trial. J Clin Psychiatry 2009, 70:1128-37.

19. Loo H, Hale A, D'Haenen $\mathrm{H}$ : Determination of the dose of agomelatine, a melatoninergic agonist and selective $5-\mathrm{HT}(2 \mathrm{C})$ antagonist, in the treatment of major depressive disorder: a placebo-controlled dose range study. Int Clin Psychopharmacol 2002, 17:239-247.

20. Kennedy SH, Emsley R: Placebo-controlled trial of agomelatine in the treatment of major depressive disorder. Eur Neuropsychopharmacol 2006, 16:93-100.

21. Olié JP, Kasper S: Efficacy of agomelatine, a MT1/MT2 receptor agonist with 5-HT2C antagonistic properties, in major depressive disorder. Int J Neuropsychopharmacol 2007, 10:661-673.

22. Bonanno G, Giambelli R, Raiteri L, Tiraboschi E, Zappettini S, Musazzi L, Raiteri M, Racagni G, Popoli M: Chronic antidepressants reduce depolarization-evoked glutamate release and protein interactions favoring formation of SNARE complex in hippocampus. J NeurosCi 2005, 25:3270-3279.

23. Michael-Titus AT, Bains S, Jeetle J, Whelpton R: Imipramine and phenelzine decrease glutamate overflow in the prefrontal cortex--a possible mechanism of neuroprotection in major depression? Neuroscience 2000, 100:681-684.

24. Tokarski K, Bobula B, Wabno J, Hess G: Repeated administration of imipramine attenuates glutamatergic transmission in rat frontal cortex. Neuroscience 2008, 153:789-795.

25. Popoli M, Musazzi L, Barbiero VS, Zappettini S, Mocaër E, Gabriel C, Mallei A, Milanese M, Giambelli R, Bonanno G, Racagni G: The novel antidepressant agomelatine reduces the release of glutamate induced by acute footshock stress in synaptosomes of prefrontal/frontal cortex. Int J Neuropsychopharmacol 2008, Suppl 1:P-01.100.

26. Musazzi L, Milanese M, Barbiero VS, Zappettini S, Tardito D, Farisello P, Bonifacino T, Mallei A, Baldelli P, Racagni G, Raiteri M, Benfenati F, Bonanno G, Popoli M: Acute stress increases depolarization-evoked glutamate release in the rat prefrontal/frontal cortex: the dampening action of antidepressants. PlOS ONE 2010, 5(1):e8566.

27. Raiteri M, Marchi M, Maura G: Chronic drug treatments induce changes in the sensitivity of presynaptic autoreceptors but not of presynaptic heteroreceptors. Eur J Pharmacol 1983, 91:141-143.

28. Pittaluga A, Raiteri L, Longordo F, Luccini E, Barbiero VS, Racagni G, Popoli $M$, Raiteri M: Antidepressant treatments and function of glutamate ionotropic receptors mediating amine release in hippocampus. Neuropharmacol 2007, 53:27-36.

29. Soumier A, Banasr M, Lortet S, Masmejean F, Bernard N, Kerkerian-Le-Goff L, Gabriel C, Millan MJ, Mocaer E, Daszuta A: Mechanisms Contributing to the Phase-Dependent Regulation of Neurogenesis by the Novel Antidepressant, Agomelatine, in the Adult Rat Hippocampus. Neuropsychopharmacology 2009, 34:2390-403.

30. Molteni R, Calabrese F, Pisoni C, Gabriel C, Mocaer E, Racagni G, Riva MA: Synergic mechanisms in the modulation of the neurotrophin BDNF following acute agomelatine administration in the rat prefrontal cortex. The World J Biol Psychiatry 2010, 11:148-53.

31. Barbiero VS, Giambelli R, Musazzi L, Tiraboschi E, Tardito D, Perez J, Drago F, Racagni G, Popoli M: Chronic antidepressants induce redistribution and differential activation of aCaM kinase II between presynaptic compartments. Neuropsychopharmacol 2007, 32:2511-2519.

32. Dekeyne A, Mannoury la Cour C, Gobert A, Brocco M, Lejeune F, Serres F, Sharp T, Daszuta A, Soumier A, Papp M, Rivet JM, Flik G, Cremers TI, Muller O, Lavielle G, Millan MJ: S32006, a novel 5-HT2C receptor antagonist displaying broad-based antidepressant and anxiolytic propertie in rodent models. Psychopharmacology (Berl) 2008, 199:549-568.

33. Vollmayr B, Henn FA: Learned helplessness in the rat: improvements in validity and reliability. Brain Res Brain Res Protoc 2001, 8:1-7.

34. Dunkley PR, Jarvie PE, Heath JW, Kidd GJ, Rostas JA: A rapid method for isolation of synaptosomes on Percoll gradients. Brain Res 1986, 372:115-129.

35. Raiteri M, Angelini F, Levi G: A simple apparatus for studying the release of neurotransmitters from synaptosomes. Eur J Pharmacol 1974 25:411-414

36. Raiteri M, Sala R, Fassio A, Rossetto O, Bonanno G: Entrapping of impermeant probes of different size into nonpermeabilized synaptosomes as a method to study presynaptic mechanisms. J Neurochem 2000, 74:423-431.

doi: $10.1186 / 1471-2202-11-68$

Cite this article as: Tardito et al., Blockade of stress-induced increase of glutamate release in the rat prefrontal/frontal cortex by agomelatine involves synergy between melatonergic and 5-HT2C receptor-dependent pathways BMC Neuroscience 2010, 11:68 